\title{
Finding of Groundwater Recharge, Transit and Discharge Areas
}

\section{Pazemes ūdens plūsmu barošanas, tranzīta un atslodzes apgabalu robežu noteikšana}

\author{
Aivars Spalviṇš $\check{1}^{1}$, Kaspars Krauklis² ${ }^{2}$ Inta Lāce ${ }^{3}$ \\ ${ }^{1-3}$ Rìgas Tehniskā universitāte, Latvija
}

\begin{abstract}
Kopsavilkums - Pazemes ūdens horizontos var definēt barošanas, atslodzes un tranzīta apgabalus, kuru eksistenci nosaka zemes virsmas reljefs un hidrogrāfiskais tīkls (upes, ezeri, jūra). Tradicionāli par barošanas apgabaliem uzskata augstienes, kurās vienlaicīgi ir infiltrācijas plūsmas un pazemes ūdens līmeṇu maksimumi. Arī Latvijas hidroğeologiskajā modelī $L A M O$ tika izmantota šāda metode. $L A M O$ dod regionāla mēroga rezultātus telpiskā hidroǵeoloğiskā sistēmā, kurā pat vienā ūdens horizontā var eksistēt būtiski atšḳirīgi hidrog̀eologiiskie apstākḷi. Šì iemesla dē lı tradicionālā metode dod neviennozīmīgus un pat kḷūdainus rezultātus. Izveidota jauna metode, kura viennozīmīgi atrisina barošanas, atslodzes un tranzìta apgabalu identifikācijas problēmu. Metode izmanto datus par pazemes vertikālo un horizontālo ūdens plūsmu ātrumiem. Metode ir rīks, kurš var dot jaunas zināšanas par Latvijas pazemes ūdens sistēmu.
\end{abstract}

Atslēgas vārdi - Hidroğeoloğiskā modelēšana, LAMO, pazemes ūdensobjekta barošanas, tranzīta un atslodzes apgabali.

\section{IEVADS}

Latvijas hidroǵeologiskais modelis LAMO reg̣ionālā mērogā apraksta procesus pazemes ūdens aktīvajā zonā [1] un ir īstenots licenzētas programmatūras "Groundwater Vistas" $(G V)$ vidē [2]. Modelī bija jānosaka pazemes ūdensobjektu barošanas, tranzīta un atslodzes apgabalu robežas. Šī uzdevuma izpratnei nepieciešama informācija par ǵeoloǵisko vidi un tās pazemes ūdens plūsmām

Izmantojot galīgo starpību metodi, ǵeoloǵiskā vide $L A M O$ ir aproksimēta ar 3D režği, kuru veido paralelipeda tipa šūnas $h \times h \times m(h-$ plaknes aproksimācijas solis, 250 metri; $m-$ mainīgs ǵeologískā slāṇa biezums).

G̣eoloǵisko vidi modelī veido 27 slāṇi. Ir divu tipu slāņi, kuru loma pazemes ūdens sistēmā ir ļoti atšķirīga: ūdens horizonti ar filtrācijas koeficientu $k=1-50, \mathrm{~m} / \mathrm{dnn}$, un sprostslān,i, kuriem $k=10^{-2}-10^{-6}, \mathrm{~m} / \mathrm{dnn}$. Ūdens horizonti ir dzeramā ūdens avoti. Sprostslāṇi nodrošina telpisku pazemes ūdens kustību ǵeologiskajā vidē.

Ūdens horizontos eksistē mainīgas vertikālās $Q_{z}$ un horizontālās $Q_{x y}$ pazemes ūdens plūsmas. Sprostslāṇos $Q_{x y} \sim 0$, $Q_{z} \sim$ const. Ši iemesla dēl barošanās, tranzīta un atslodzes apgabalus var noteikt tikai ūdens horizontiem.

Barošanās un tranzīta apgabalos $Q_{z}>0$; atslodzes apgabalā $Q_{z}<0$, un tā robežu veido $Q_{z}=0$ līnija. Tranzīta apgabali savieno barošanas un atslodzes apgabalus. Barošanas apgabala robežas atrašana nav triviāls uzdevums, tāpēc ka apgabalā vienlaicīgi ir $Q_{x y}$ un $Q_{z}$ plūsmas, bet pazīme $Q_{z}>0$ nav pietiekama šīs robežas viennozīmīgai noteikšanai.

Rakstā piedāvāta jauna metode, kura izmanto plūsmas $Q_{x y}$ un $Q_{z}$ barošanas, tranzìta un tranzīta apgabalu robežu noteikšanai. Iztirzāti šobrīd izmantotās metodes trūkumi.

\section{BAROŠANAS APGABALA NOTEIKŠANA AR TRADICIONĀLO METODI}

Tradicionāli par barošanas apgabaliem uzskata augstienes, jo tur vienlaicīgi eksistē plūsmas $Q_{z}$ un pazemes ūdens līmeņu $\varphi$ maksimumi. Līmeņus $\varphi$ šūnu $h \times h \times m$ centros aprēķina $G V$ kā $61.56 \times 10^{6}$ kārtas (mezglu skaits LAMO 3D režğî) algebrisko vienādojumu sistēmas atrisinājumu:

$$
A \varphi=\boldsymbol{\beta}-G \boldsymbol{\psi}
$$

kur $A$ - ǵeolog̣iskās vides ūdensvadāmību matrica, kura izmanto datus par ǵeoloǵisko slāṇu virsmām ( $z$ kartes) un filtrācijas koeficientiem ( $k$ kartes);

$\boldsymbol{\beta}$ - pazemes plūsmu robežnoteikumu vektors;

$\boldsymbol{\psi}$ - pazemes ūdens līmeņu robežnoteikumu vektors;

$G-\boldsymbol{\psi}$ noteikumu saites matrica ar ǵeoloǵisko vidi.

Atrisinot sistēmu (1), aprēḳina plūsmas katras elementārās šūnas sešās virsmas plaknēs: augšas un apakšas $h \times h$ plaknēs vertikālās plūsmas $Q_{z}, \mathrm{~m}^{3} / \mathrm{dnn}$, ar ātrumu $v_{z}=Q_{z} / h^{2}, \mathrm{~m} / \mathrm{dnn}$, un horizontālās plūsmas sānu plaknēs $h \times m Q_{x}$ un $Q_{y}, \mathrm{~m}^{3} / \mathrm{dnn}$, ar ātrumiem $v_{x}=Q_{x} /(h \times m)$ un $v_{y}=Q_{y} /(h \times m), \mathrm{m} / \mathrm{dnn}$. Plūsmas $Q_{x}, Q_{y}, Q_{z}$ izmanto bilances aprēksinos, bet ātrumi $v_{x}, v_{y}, v_{z}$ ir būtiski ūdens dalinu trasēšanas programmas MODPATH darbībai [3]. Šie ātrumi šūnu ieejas plaknēs ir brīvi pieejami modelētājam.

Tradicionālā barošanas tranzīta un atslodzes apgabala noteikšanas metode izmanto ātrumu $v_{z}$ šūnas augšpusē infiltrācijas karšu iegūšanai:

$$
\text { inf, } \mathrm{mm} / \operatorname{gad} \overline{\mathrm{a}},=365 \times 10^{3} v_{z} .
$$

Barošanas apgabalu noteikšanai metode izmanto kartes, kurās savietoti infiltrācijas, mm/gadā, un līmeņu $\varphi, \mathrm{m}$ vjl., sadalījumi. 


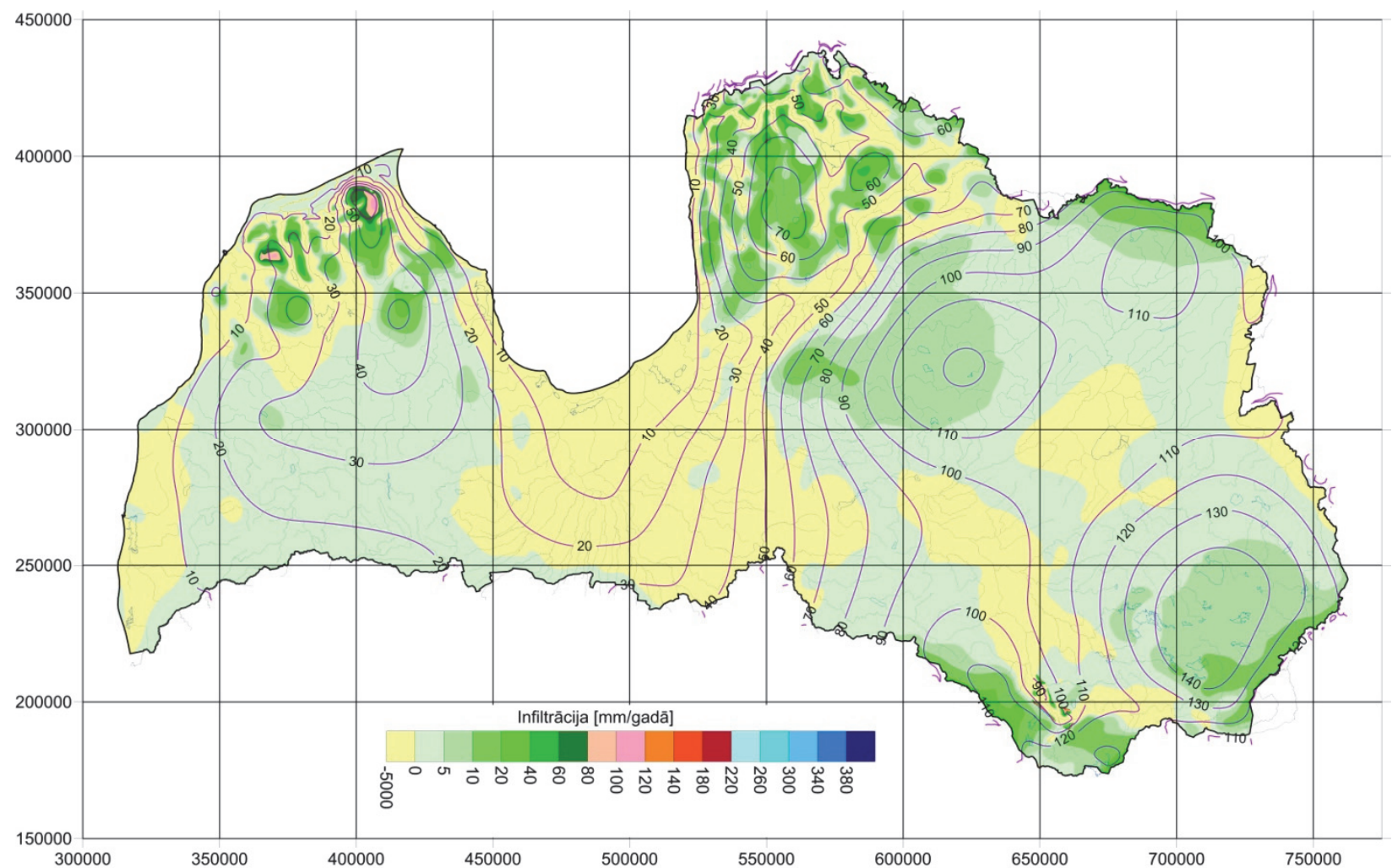

1. att. Infiltrācijas plūsma un ūdens līmeṇi D2ar horizontam (LAMO 25. slānim).

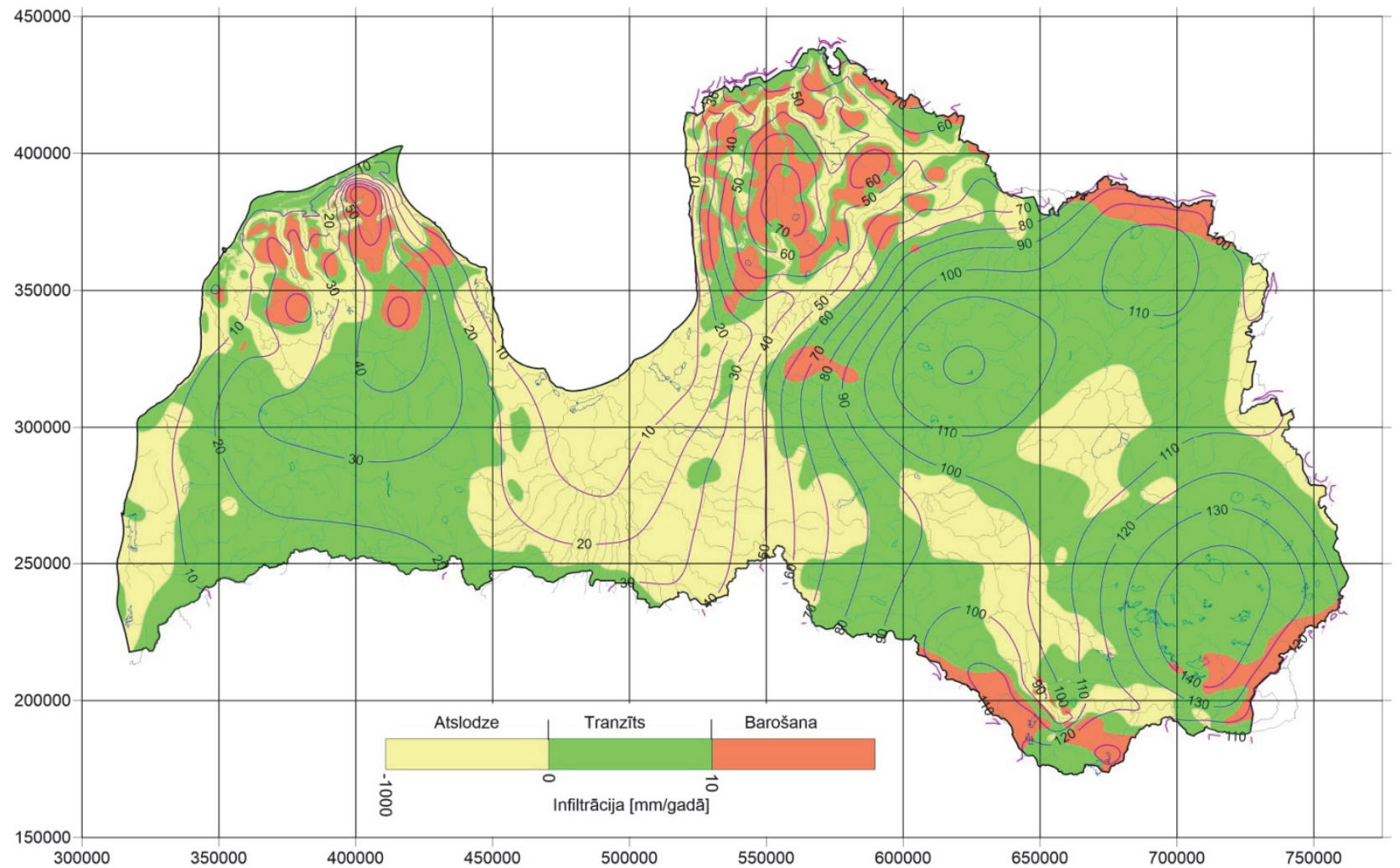

2. att. Pazemes ūdens barošanas, tranzīta un atslodzes apgabali D2ar horizontam (LAMO 25. slānim) pēc tradicionālās metodes. 
Šādas kartes piemērs skatāms 1. attēlā ūdens horizontam D2ar (LAMO 25. slānis), kurš ir Latvijas aktīvās pazemes ūdeņu zonas apakšèjā daḷa [4]. Slān̄̄ eksistē būtiski atšķirīgi infiltrācijas apstākḷi tā seklajā ziemeḷu un dzilajās vidus un dienvidu daḷās. Tāpēc tradicionālā metode nav identificējusi barošanas apgabalus D2ar slān̄̄ zem Vidzemes un Latgales augstienēm, kurās inf $<10 \mathrm{~mm} /$ gadā (skatît 2. attēlu).

Tradicionālās metodes galvenais trūkums ir nepieciešamība katram ūdens horizontam un pat tā daḷām izmantot atškikīīgus lokālo infiltrācijas maksimumu sliekšņus. Ja hidroǵeoloǵiskie apstākḷi horizontā ir būtiski atškirīgi (kā D2ar), tad metode visus lokālos barošanas apgabalus nespēj atrast.

Tāpēc, ka tiek izmantots tikai ātrums $v_{z}$ slāņu augšpusē, tradicionālā metode barošanas apgabalu "atrod" arī neeksistējošā slānī (LAMO tā biezums $\mathrm{m}=0,02 \mathrm{~m}$ ) un sprostslānī, jo šajos slāņos eksistē savietoti ūdens līmeṇu $\varphi$ un infiltrācijas plūsmu maksimumi.

Sprostslāņos un neeksistējošos slāņos plūsmu ātrumi $v_{z i}$ un $v_{z i+1}$ i-tā slāņa augšpusē un apakšpusē ir vienādi. Ja izmanto šo ātrumu starpību $\Delta_{i}$ :

$$
\Delta_{i}=v_{z i}-v_{z i+1},
$$

tad šādos slāṇos $\Delta_{i}=0$, t. i., tiem nevar definēt barošanas, tranzìta un atslodzes apgabalus.

Formula (3) i-tajam LAMO slānim dod vertikālās plūsmas ātrumu $\Delta_{i}$, kurš ir proporcionāls rezultējošajai vertikālajai pazemes ūdens plūsmai $Q_{\text {rezi: }}$ :

$$
Q_{z \mathrm{rezi}}=Q_{z i}-Q_{z i+1}=h^{2} \Delta_{i},
$$

kuru izmanto $G V$ rīks “Mass balance" pazemes ūdens plūsmu lokālās bilances aprēḳinam [4]. Ūdens horizontiem $Q_{z \mathrm{rez}}$ nav vienāda ar nulli un ir plūsma, kura baro horizontu. Tāpēc $\Delta_{i}$ izmantošana ir būtiska viennozīmīgas barošanas apgabala robežas atrašanai.

\section{UZLABOTĀ BAROŠANAS APGABALU MEKLĒŠANAS METODE}

Uzlabotajai metodei $i$-tajam ūdens horizontam barošanas, tranzīta un atslodzes apgabalu identifikācijai izmantota bezdimensionāla funkcija:

$$
r_{i}=250 \frac{\Delta_{i}}{k_{i} \operatorname{grad} \varphi_{i}} ; \quad k_{i} \operatorname{grad} \varphi_{i}=v_{x y i}=\sqrt{v_{x i}^{2}+v_{y i}^{2}} .
$$

kur $\Delta_{i}$ - rezultējošais vertikālās plūsmas ātrums formulā (3);

$v_{x y i}$ - horizontālās plūsmas rezultējošais ātrums;

$v_{x i}, v_{y i}-\bar{a}$ trumi elementārās šūnas ieejas sānu plaknēs;

$k_{i}, \varphi_{i}$ - filtrācijas koeficientu un ūdens līmeṇu sadalījumi; 250 - empīriska konstante.

Barošanas, tranzīta un atslodzes apgabaliem atbilst funkcijas $r$ vērtības: $r \geq 1$ - barošana; $1>r>0$ - tranzīts; $r<0$ - atslodze. Atslodzes apgabalā var noteikt "negatīvā" tranzīta zonu $(-1<r<0)$ un apgabala centrālo daḷ, kurā $r<-1$. Robežu $r=1$ un $r=-1$ novietojumu nosaka empīriskās konstantes izvēle. Ja horizonts neeksistē, $r=0$.
Formulā (5) horizontālais ātrums $v_{x y}$ aizstāts ar izteiksmi $k_{i} \operatorname{grad} \varphi_{i}$ šādu apsvērumu dēḷ:

- var veikt aprēķinu arī tad, ja nav iegūstami ātrumi $v_{x}$ un $v_{y}$ (slān,os ar noteikumu $\boldsymbol{\psi}$ );

- $\operatorname{grad} \varphi_{i}$ aprēḳina precīzāk ar SURFER [5] laukumā $2 h \times 2 h$, bet $G V \operatorname{dod} v_{x}$ un $v_{y}$ laukumā $h \times h$;

- $\operatorname{grad} \varphi_{i}$ samazinās ūdens līmeña $\varphi$ maksimuma un minimuma vietās, un tāpēc barošanas un atslodzes apgabalos veidojas funkcijas $r$ lokālie ekstrēmumi [6].

Funkcija $r=0$ ūdens horizonta neeksistējošā daḷă $(m=0)$, kur $\Delta_{i}=0$ un ātrums $\left|v_{x y}\right|>0$ nav atkarīga no horizonta biezuma $m$. Tāpēc formulu (5) var izmantot horizontiem, kuri nav nepārtraukti (kā lielākā daḷa $L A M O$ slāņu).

Zem lieliem ezeriem grad $\varphi \sim 0$, tāpēc šeit formula (5) dod lielas $r$ vērtības.

Izteiksmi (5) nedrīkst izmantot sprostslāṇos, jo tiem $\Delta_{i} \sim 0$; $k \operatorname{grad} \varphi \sim 0$, t. i., rodas nenoteiktība $0 / 0$.

Uzlabotās metodes izmantošanas rezultāts horizontam D2ar skatāms 3. attēlā, kur ar krāsu skalas palīdzību dots detalizēts funkcijas $r$ attēlojums barošanas, tranzīta un atslodzes apgabalos:

- ir atrasti visi horizonta lokālie barošanas apgabali Latvijas augstienēs;

- pazemes procesu intensitāte visos trijos apgabalos ir mainīga, par ko liecina $r$ raksturs;

- atslodzes apgabala robežas 2. un 3. attēlā ir atšksirīgas, jo $r=0$ linijas novietojumu 3. attēlā nosaka âtrums $\Delta_{i}=0$, bet 2 . attēlā - ātrums $v_{z}=0$.

Atšķirībā no tradicionālās metodes uzlabotā metode tieši neizmanto datus par infiltrācijas plūsmas un līmeņu $\varphi$ maksimumiem, jo to ietekmi nosaka attiecība $\Delta_{i} / v_{x y i}$ formulā (5). Tomēr 3. attēla kartē parādītas arī $\varphi$ izolīnijas, jo tās modelētājam palīdz izprast barošanas, tranzīta un atslodzes apgabalu noteikšanas rezultātu.

Uzlabotā metode sekmīgi darbojas visos ūdens horizontos, un nav nepieciešama empīiskās konstantes izmaiņa. Jauno metodi varēs izmantot kā rīku telpiskai barošanas, tranzīta un atslodzes apgabalu robežu telpisku izmaiņu pētījumiem $L A M O$ vidē.

Metode ar detalizētu $r$ gradāciju ir lietota LAMO diagnostikai un model̦a sākuma datu koriǵḡěsanai.

Ja aprobežojas ar barošanas, tranzīta un atslodzes apgabalu robežu noteikšanu, tad kartē tiek attēlotas trīs zonas, kurās $r>1 ; 1>r>0$ un $r<0$. Tad 3. attēla karte iegūst šo apgabalu tradicionālo attēlojumu (skatît 4 . attēlu.).

Jaunās metodes pirmie rezultāti apstiprina, ka pazemes ūdens plūsmu barošana, tranzīts un atslodze ir atkarīgi no virsmas reljefa un hidrogrāfiskā tīkla ietekmes līdz pat aktīvās pazemes ūdens zonas apakšējai dal̦ai. Šāda īpašība nepiemīt upju baseinu sateces apgabaliem, kuru robežas saglabājās tikai kvartāra slāṇos [7], [8]. 


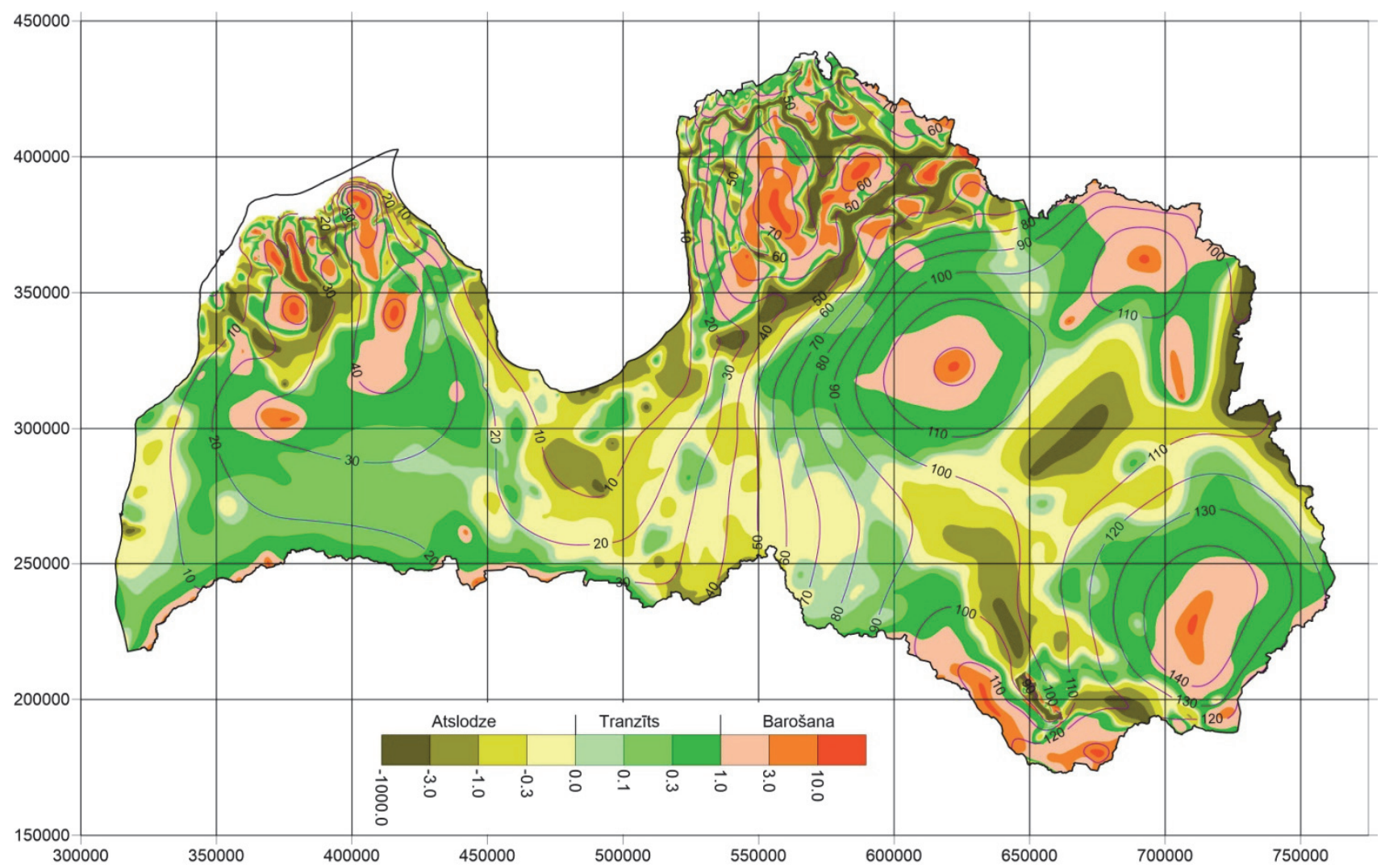

3. att. Atslodzes, tranzīta un barošanas apgabali D2ar horizontam (LAMO 25. slānim) ar detalizētu funkcijas $r$ attēlojumu.



4. att. Atslodzes, tranzīta un barošanas apgabali D2ar horizontam (LAMO 25. slānim) ar tradicionālu funkcijas $r$ attēlojumu. 


\section{SECINĀJUMI}

Izstrādāta jauna metode pazemes ūdens plūsmu barošanas, tranzìta un atslodzes apgabala robežu noteikšanai.

Metode pielietota Latvijas hidroǵeoloğiskā modeḷa LAMO datu apstrādāšanai. Pirmie rezultāti liecina, ka metodi varēs lietot kā rīku jaunu zināšanu iegūšanai par procesiem Latvijas pazemes ūdens sistēmā.

Metode sekmīgi izmantota $L A M O$ diagnostikai un modęla sākuma datu koriǵēšanai.

Metode izstrādāta, īstenojot Valsts pētījumu programmu "EVIDEnT".

\section{LITERATŪRAS SARAKSTS}

[1] A. Spalviṇš "Latvijas hidroǵeologiiskā modeḷa izveidošana Rīgas Tehniskajā universitātē," Rīgas Tehniskās universitātes zinātniskais žurnāls Datormodelēšana un robežproblēmas, 55. sēj., 5.-11. lpp., 2016.

[2] Environmental Simulations, Inc. Groundwater Vistas. Version 6, Guide to using, 2011.

[3] D. W. Pollok, User's Guide for MODPATH/MODPATH-Plot, Version3. A particle tracking post-processing package for MODFLOW, the US Geological Survey finite-difference groundwater flow model, U.S. Geological survey, Sep. 1994 [Online]. Available:

https://pubs.usgs.gov/of/1994/0464/report.pdf

[4] Projekta "Pazemes ūdensobjektu kartēšana Gaujas upju baseina apgabalā" materiāli, Rīga: Rīgas Tehniskā universitāte, 12 lpp., 2013. 49 kartes, 6 tabulas, [Online]. Available: http://www.emc.rtu.lv/

[5] Golden Software, Inc., SURFER-13 for Windows, Users manual, Guide to Using, 2015.

[6] B. Silinga un K. Šteinerts. Rokasgrāmata matemātikā, Rīga: Zvaigzne ABC, 367 lpp., 2006.

[7] P. A. DeBarry, Watersheds: processes assessment and management. New Jersey: Willey and Sons Inc. Hoboken, p. 700, 2004.

[8] K. Krauklis, A. Spalviņš un I. Eglīte "Latvijas zemieņu un augstienุu upju īpašīibu pētišana ar Latvijas hidroğeologiskā modeḷa palīdzību," Datormodelēšana un robežproblēmas, 55. sēj., 28.-33. lpp., 2016.



Aivars Spalviñš was born in Latvia. In 1963, he graduated from the Riga Polytechnical Institute (since 1990 - Riga Technical University) as a Computer Engineer. A. Spalviņs is the Head of the Environment Modelling Centre of RTU. His research interests include computer modelling of groundwater flows and migration of contaminants.

E-mail: Aivars.Spalvins@rtu.lv

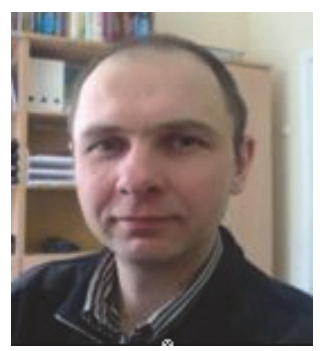

Kaspars Krauklis received the Master's degree in Computer Systems from the Riga Technical University in 2007 and the Certificate in Teaching of Engineering Sciences from the Institute of Humanities of RTU in 2005. He is a researcher at the Environment Modelling Centre of RTU.

E-mail: kasparskrauklis@gmail.com

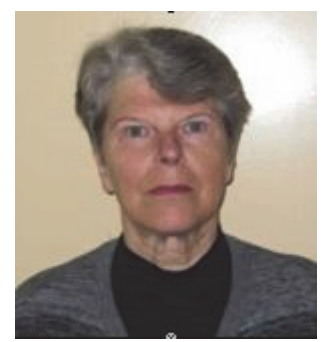

Inta Lāce was born in Latvia. In 1971, she graduated from Riga Polytechnical Institute (since 1990 - Riga Technical University) as a Computer Engineer. In 1995, I. Lāce received the Master's degree in Applied Computer Science. Since 1991, she is a researcher at the Environment Modelling Centre of RTU.

E-mail: intalace@yahoo.com

Finding of Groundwater Recharge, Transit and Discharge Areas Aivars Spalviṇšs ${ }^{1}$, Kaspars Krauklis ${ }^{2}$, Inta Lāce ${ }^{3}$

${ }^{1-3}$ Riga Technical University, Latvia

Groundwater recharge, transit and discharge areas for aquifers must be found. Their location depends on the influence of ground surface and hydrographical network (rivers, lakes, sea). It is commonly agreed that the recharge areas are located at hilly places where maximums of infiltration flows and piezometric groundwater levels coincide. Such method was applied for the hydrogeological model of Latvia $L A M O$. The model provides results for a complex spatial hydrogeological system where conditions even within one aquifer may differ considerably. For this reason, the common method of finding recharge, transit and discharge areas fails to provide accurate results. The new method has been developed. It is based on appliance of the ratio for velocities of vertical to horizontal groundwater flows. The resulting velocity of the vertical flow is found as the difference of velocities of flows on the top and bottom surfaces of the aquifer. The ratio $r$ is the non-dimensional function. Its values $r=1$ and $r=0$ determine the locations of boundaries for the recharge and discharge areas, accordingly. For the transit area $0<r<1$. Within the recharge and discharge areas $r>1$ and $r<1$, correspondingly. The new method provides accurate results even for discontinuous aquifers where the zones of zero thickness appear. Within such zones $r=0$. The method will be applied as a tool for investigating complex groundwater processes that are modelled by $L A M O$. The method was used for extra calibration of $L A M O$ in order to improve its results.

The research was supported by the Latvian State Research Program EVIDEnT

Keywords - Hydrogeological modelling, LAMO, recharge, transit and discharge areas. 